\title{
GERMINAÇÃO DE SEMENTES DE SENNA OBTUSIFOLIA (L.) H. S. IRWIN \& BARNEBY (FABACEAE) VISANDO A RESTAURAÇÃO DE ÁREAS DEGRADADAS
}

\author{
GERMINATION OF SENNA OBTUSIFOLIA (L.) IRWIN \& BARNEBY \\ (FABACEAE) AIMING THE RESTORATION OF DEGRADED AREAS
}

\author{
Larissa Regina TOPANOTTI ${ }^{1}$, Paula Helena PEREIRA ${ }^{1}$, Fernando Campanhã \\ BECHARA $^{2 *}$ \\ 1 Universidade Tecnológica Federal do Paraná - UTFPR. Campus Dois \\ Vizinhos, PR. Estrada para Boa Esperança Km 04. Comunidade São Cristóvão \\ 85560-000 - Dois Vizinhos, PR - Brasil. \\ $2^{2 *}$ Autor para contato: Universidade Tecnológica Federal do Paraná - UTFPR. Campus \\ Dois Vizinhos, PR. Estrada para Boa Esperança Km 04. Comunidade São Cristóvão \\ 85560-000 - Dois Vizinhos, PR - Brasil. E-mail: bechara@utfpr.edu.br
}

Data de recebimento: 20/02/2014

Data da aprovação: 30/07/2014

RESUMO

Senna obtusifolia é uma espécie arbustiva pioneira, com excelente potencial para restauração de áreas degradadas. No entanto, algumas espécies do gênero Senna apresentam sementes dormentes, necessitando de um processo para aceleração da germinação de sementes e, consequentemente, formação de mudas. O objetivo desse trabalho foi verificar o índice de germinação mais eficiente conforme o tempo de imersão de sementes de $S$. obtusifolia em água quente. Foram aplicados cinco tratamentos às sementes: T1 - testemunha; T2 - imersão em água à temperatura ambiente; T3 imersão em água à temperatura de $40^{\circ} \mathrm{C}$; T4 -imersão em água à temperatura de $75^{\circ} \mathrm{C}$; e T5 - imersão em água à temperatura de $90^{\circ} \mathrm{C}$. As sementes foram depositadas em um béquer com água destilada e aquecidas até a temperatura do tratamento, sendo depois embebidas por 18 horas. As sementes de S. obtusifolia não apresentaram dormência tegumentar, mas o tratamento com água a $75^{\circ} \mathrm{C}$ favoreceu a germinação das sementes, sendo a sua aplicação recomendada para recobrimento do solo através de semeadura direta em projetos comerciais de restauração em larga escala.

Palavras-chave: Dormência. Espécies pioneiras. Restauração ecológica.

\begin{abstract}
Senna obtusifolia is a pioneer shrub species with excellent potential for restoration of degraded areas. However, some species of the genus Senna exhibit seeds dormancy, requiring a process for accelerating the germination and formation of seedlings. The aim of this work was to analyze the germination of S. obtusifolia using hot water, because it is an easy method to apply in commercial projects. Five treatments were applied to seeds: $\mathrm{T} 1$ - control, $\mathrm{T} 2$ - immersion in water at room temperature: T3 - immersion in water at $40^{\circ} \mathrm{C}, \mathrm{T} 4$ - immersion in water at $75^{\circ} \mathrm{C}$ and $\mathrm{T} 5$ - immersion in water at $90^{\circ} \mathrm{C}$. The seeds were placed in a beaker with distilled water and heated to the treatment temperature, and then imbibed for 18 hours. Higher germination percentages were observed in treatments 4 and 5, but all treatments were equal according to the Tukey test. The seeds of $S$. obtusifolia showed no cutaneous dormancy, but treatment with water at $75^{\circ} \mathrm{C}$ enhanced germination of seeds and its application can be recommended for soil covering through direct seeding in commercial projects of restoration in large scale.
\end{abstract}

Keywords: Dormancy. Ecological restoration. Pioneer species. 


\section{Introdução}

Em qualquer procedimento de restauração ecológica, o uso de espécies pioneiras de rápido crescimento é fundamental, pois elas facilitam o início de uma dinâmica sucessional, principalmente pelo sombreamento e incorporação de nutrientes (RODRIGUES et al., 2009; REIS et al., 2010). Além disso, as espécies pioneiras recobrem precocemente o solo, incorporando matéria orgânica e inibindo o desenvolvimento de espécies exóticas invasoras. Neste cenário, as plantas estrategistas e herbáceoarbustivas são as mais agressivas e colonizadoras, tornando-se aptas para a base do processo de sucessão secundária (BECHARA et al., 2007).

Uma espécie ruderal com alto potencial para restauração de áreas degradadas é Senna obtusifolia L. H. S. Irwin \& Barneby, conhecida popularmente como fedegoso, mata-pasto, pau-verde ou mamangá. Trata-se de um arbusto que pode atingir uma altura de $70 \mathrm{~cm}$ a $160 \mathrm{~cm}$ (LORENZI, 2000), da família Fabaceae, com distribuição ampla no Brasil, ocorrendo nos biomas brasileiros da Amazônia, Caatinga, Pantanal e Mata Atlântica, incluindo a Floresta Ombrófila do estado do Paraná (SOUZA; BORTOLUZZI, 2012; KISSMANN; GROTH, 1999). Além de ser espontânea nestes biomas brasileiros, também apresenta distribuição pantropical, sendo encontrada em lugares como o Havaí (WAGNER et al., 1999), Ilhas de Galápagos (MCMULLEN, 1999) e Austrália (SMITH, 2002).

S. obtusifolia ocorre em áreas de vegetação secundária pioneira, infestando áreas de lavouras perenes e pastagens. Pode representar uma ameaça se as folhas forem ingeridas in natura por bovinos, já que tem potencial tóxico. Em contrapartida, as sementes e as raízes podem ser usadas na medicina alternativa, e as sementes também têm se apresentado como componente para uma apetitosa bebida, que pode ser empregada no lugar no café (KISSMANN; GROTH, 1999; SOUSA, 2004), além do seu potencial para recuperação de áreas degradadas.

Quanto à presença de nódulos fixadores de nitrogênio nas raízes, comum nas leguminosas, Sprent (2001) observa que existem 243 espécies de Senna, das quais 208 foram reportadas como nodulantes. Entretanto, S. obtusifolia é citada por alguns autores como uma espécie que não apresenta nódulos fixadores de nitrogênio (SAMBA et al., 2002; LORENZI, 2000).
Trata-se de uma espécie pioneira anual, cujas flores são hermafroditas, arquiclamídeas, com frutos do tipo legume deiscente e sementes autocóricas, as quais geralmente possuem alta viabilidade, normalmente acima de 90\%, segundo Kissmann e Groth (1999). Entretanto, as sementes das espécies da família botânica Fabaceae apresentam dormência devido à rigidez do tegumento, sendo altamente impermeáveis (SOUZA et al., 2008), e algumas espécies herbáceas do gênero Senna apresentam sementes dormentes, como Senna occidentalis (L.) Linck. Handb. (FOWLER; CARPANEZZI, 1997), Senna siamea (Lam.) H. S. Irwin e Barneby (DUTRA et al., 2007) e Senna spectabilis (DC.) Irwin e Barneby (SOUZA et al., 2008), o que dificulta temporariamente a germinação e prolonga a viabilidade das sementes por mais tempo (FLORIANO, 2004). Adicionalmente, a dormência tegumentar pode tornar-se um empecilho para a produção de mudas (FOWLER; CARPANEZZI, 1997).

No caso de $S$. obtusifolia, segundo Kissmann e Groth (1999), a temperatura ideal para a germinação das sementes dessa espécie encontra-se na faixa entre $24{ }^{\circ} \mathrm{C}$ e $36{ }^{\circ} \mathrm{C}$, portanto, a emergência ocorre geralmente em altos índices no verão e na primavera. Algumas sementes podem germinar no outono ou início de inverno, gerando plantas que não alcançam grande desenvolvimento vegetativo, porém podem florescer e produzir frutos.

Embora as espécies herbáceo-arbustivas nativas pioneiras exerçam um papel fundamental na recuperação de áreas degradadas devido ao rápido recobrimento do solo e atração precoce de fauna, ainda são muito incipientes os estudos a respeito da biologia, ecologia, técnicas de propagação e manejo das mesmas (RANIERI et al., 2003), assim como a comercialização de suas sementes.

Por produzir grandes quantidades de sementes de fácil coleta em áreas abandonadas e bordas de estrada de diversos ecossistemas, as sementes de Senna obtusifolia possuem grande potencial para sua comercialização e composição de coberturas vivas de solos degradados.

Dentro deste contexto, o objetivo do presente estudo foi efetuar a análise da germinação de sementes de $S$. obtusifolia utilizando água quente, por tratar-se de método de fácil aplicação em projetos comerciais de larga escala. 


\section{Material e método}

A área de coleta de sementes de $S$. obtusifolia está localizada na comunidade de Canoas, zona rural do município de Dois Vizinhos, sudoeste do Paraná, entre as coordenadas geográficas $25^{\circ} 40^{\prime} 05^{\prime \prime} \mathrm{S}$ e $53^{\circ} 09^{\prime} 23^{\prime}$ W, com altitude média de $464 \mathrm{~m}$. O solo é classificado como latossolo vermelho, a umidade do ar gira em torno de $64 \%$ a $74 \%$ e a precipitação média anual varia entre 1.800 a $2.200 \mathrm{~mm}$ (MAACK, 1981). Segundo a classificação de Köppen, o município apresenta clima subtropical úmido (Cfa), sem estação seca, sendo $14{ }^{\circ} \mathrm{C}$ a média do mês mais frio, e $23,6{ }^{\circ} \mathrm{C}$ a do mês mais quente, ocorrendo uma geada a cada pelo menos dois anos (CARAMORI et al., 2001).

As sementes foram coletadas de 12 matrizes de uma população colonizadora de uma área degradada, colonizada por gramíneas exóticas, como Brachiaria spp., e colocadas para germinar no dia seguinte à coleta. Foram aplicados cinco tratamentos às sementes, com diferentes temperaturas, a saber: tratamento 1 (T1) - testemunha (sem imersão em água); tratamento 2 (T2) - imersão em água com temperatura ambiente; tratamento 3 (T3) - imersão em água à temperatura de $40{ }^{\circ} \mathrm{C}$; tratamento $4(\mathrm{~T} 4)$ - imersão em água à temperatura de $75{ }^{\circ} \mathrm{C}$; e tratamento 5 (T5) - imersão em água à temperatura de $90^{\circ} \mathrm{C}$. Cada tratamento foi constituído pela deposição de água destilada em um béquer, que foi aquecido até atingir a temperatura correspondente, com exceção da testemunha. Depois os recipientes foram retirados do aquecimento e, então, as sementes foram imersas nos béqueres, permanecendo embebidas por 18 horas. Cada tratamento contou com 400 sementes e foi organizado em 8 repetições de 50 sementes cada, num total de 2.000 sementes utilizadas, em delineamento inteiramente casualizado. Em seguida, as sementes foram distribuídas em caixas de germinação (11 x 11 x 3,5 cm), forradas com papel Germtest e mantidas úmidas em câmara BOD sob as condições de $26 \pm 1$ ${ }^{\circ} \mathrm{C}$ e fotoperíodo de 12 horas.

As avaliações foram feitas a cada 48 horas, durante um período de 42 dias. Foram consideradas sementes viáveis as plântulas que apresentaram cotilédones. Os tratamentos foram comparados estatisticamente por meio de análise de variância e teste de comparação de médias (Tukey), com o auxílio do Software Assistat ${ }^{\circledR}$.

\section{Resultados}

As maiores porcentagens de germinação das sementes foram observadas nos tratamentos $\mathrm{T} 4$ (imersão em água a $75^{\circ} \mathrm{C}$ ) e T5 (imersão em água a $90{ }^{\circ} \mathrm{C}$ ), com $77 \%$ e $72,75 \%$, respectivamente. Entretanto, todos os tratamentos não diferiram estatisticamente entre si pelo teste de Tukey (Tabela 1).

Tabela 1- Porcentagem média de germinação das sementes de Senna obtusifolia após aquecimento e imersão em água destilada por 18 horas, no final de 42 dias de avaliação

\begin{tabular}{l|c}
\hline \multicolumn{1}{c|}{ Tratamento } & $\begin{array}{c}\text { Germinação } \\
\text { (\%) }\end{array}$ \\
\hline T4: imersão em água à temperatura de $75^{\circ} \mathrm{C}$ & $77 \mathrm{a}$ \\
\hline T5: imersão em água à temperatura de $90^{\circ} \mathrm{C}$ & $72,75 \mathrm{a}$ \\
\hline $\begin{array}{l}\text { T2: imersão em água com temperatura } \\
\text { ambiente }\end{array}$ & $68,25 \mathrm{a}$ \\
\hline T3: imersão em água à temperatura de $40^{\circ} \mathrm{C}$ & $67,5 \mathrm{a}$ \\
\hline T1: testemunha (sem imersão em água) & $63,5 \mathrm{a}$ \\
\hline
\end{tabular}

Médias com as mesmas letras não diferem entre si pelo teste de Tukey a 5\% de significância.

Na figura 1 observa-se a germinação acumulativa média por tratamento ao longo do tempo. Aos 6 dias de implantação do experimento, os tratamentos não resultaram em diferenças consideráveis. A partir dos 18 dias, as porcentagens de germinação tornaram-se notadamente diferentes entre si.

Figura 1- Germinação de sementes de Senna obtusifolia sob diferentes tratamentos. T1 - testemunha (sem imersão em água); T2 - imersão em água com temperatura ambiente; T3 - imersão em água à temperatura de $40^{\circ} \mathrm{C}$; T4 - imersão em água à temperatura de $75^{\circ} \mathrm{C}$; T5 - imersão em água à temperatura de $90{ }^{\circ} \mathrm{C}$

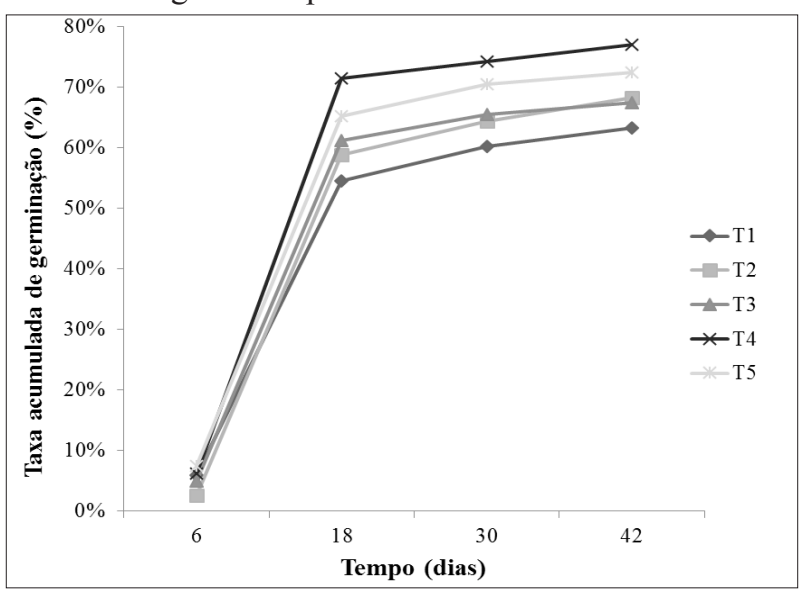

Publ. UEPG Ci. Biol. Saúde, Ponta Grossa, v.20, n.2, p. 125-129, jul./dez. 2014 Disponivel em <http://www.revistas2.uepg.br/index.php/biologica> 


\section{Discussão}

A presença de dormência das sementes de S. obtusifolia não foi verificada, pois se nota que as sementes do tratamento testemunha tiveram percentagens de germinação $(63,5 \%)$ estatisticamente iguais aos demais tratamentos. No entanto, a utilização de água sob mais altas temperaturas favoreceu a germinação, e pode ser recomendada para essa espécie em projetos comerciais de restauração de áreas degradadas.

A imersão em água quente é um método muito prático que é utilizado para acelerar a germinação de sementes de espécies de Senna, principalmente em projetos técnicos e comerciais (SANTARÉM; AQUILA, 1995; SOUZA et al, 2008). Adicionalmente, as sementes de $S$. obtusifolia são bem menos exigentes com relação à umidade do que as sementes de, por exemplo, soja (Glycine $\max (\mathrm{L}$.) Merrill), o que lhe confere vantagem quanto à germinação, permitindo o surgimento de plântulas em épocas mais secas (KISSMAN; GROTH, 1999). Isto pode explicar o fato de as sementes não imersas em água (tratamento testemunha) terem germinado facilmente, devido a essa sua característica de emergir mesmo em condições de baixa umidade.

A aceleração da germinação de sementes para recobrimento do solo, via semeadura direta em recuperação de áreas degradadas, é imprescindível para que as sementes germinem prontamente e sincronicamente, permitindo uma eficiente implantação de coberturas vivas (MATTEI; ROSENTHAL 2000; SANTOS et al., 2012)

Considerando os resultados obtidos, nota-se que as sementes de S. obtusifolia não apresentaram dormência tegumentar. Entretanto, recomenda-se a imersão de suas sementes em água a $75{ }^{\circ} \mathrm{C}$, seguida de embebição por 18 horas, para acelerar o recobrimento do solo através de semeadura direta em projetos comerciais de restauração de áreas degradadas. Finalmente, encorajam-se maiores estudos sobre germinação de espécies pioneiras herbáceo-arbustivas nativas, permitindo a sua comercialização e uso pelos projetistas.

\section{Agradecimentos}

Agradecemos ao PET Engenharia Florestal, da Universidade Tecnológica Federal do Paraná, Câmpus Dois Vizinhos, pela concessão das bolsas às au- toras durante a realização do presente trabalho, e à Roseli Lopes da Costa Bortoluzzi e Camila Maistro Patreze, pelas contribuições.

\section{Referências}

BECHARA, F. C.; FERNANDES, G. D.; SILVEIRA, R. L. Quebra de dormência de sementes de Chamaecrista flexuosa (L.) Greene Leguminosae visando a restauração ecológica do Cerrado. Revista de Biologia Neotropical, v. 4, n. 1, p. 58-63, 2007.

CARAMORI, P. H., CAVIGLIONE, J. H.; WREGE, M. S.; GONÇALVES, S. L.; FARIA, R. T.; ANDROCIOLI FILHO, A.; SERA, T.; CHAVES, J. C. D.; KOGUISHI, M. $\mathrm{S}$. Zoneamento de riscos climáticos para a cultura de café (Coffea arabica L.) no estado do Paraná. Revista Brasileira de Agrometeorologia, v. 9, n. 3, p. 486-494, 2001.

DUTRA, A. S., MEDEIROS FILHO, S.; TEÓFILO, E. M.; DINIZ, F. O. Germinação de sementes de Senna siamea (Lam.) H. S. Irwin \&Barneby - Caesalpinoideae. Revista Brasileira de Sementes, v. 29, n. 1, p. 160-164, 2007.

FLORIANO, E. P. Germinação e dormência de sementes florestais. Santa Rosa, RS: ANORGS, 2004, p. 1 - 22. (Caderno didático, 2).

FOWLER, J.A. P.; CARPANEZZI, A. A. Quebra de dormência tegumentar de sementes de fedegoso. Colombo: Embrapa Florestas, 1997, p. 1-2. (Comunicado Técnico, 15).

KISSMANN, K. G.; GROTH, D. Plantas infestantes e nocivas. São Paulo: BASF, 1999. 980 p.

LORENZI, H. Plantas daninhas do Brasil: terrestres, aquáticas, parasitas e tóxicas. Nova Odessa, SP: Instituto Plantarum, 2000. $672 \mathrm{p}$.

MAACK, R. Geografia física do Estado do Paraná. Rio de Janeiro: J. Olympio, 1981. 450 p.

MATTEI, V. L.; ROSENTHAL, M. D. Semeadura direta de canafístula (Peltophorum dubium (Spreng.) Taub.) no enriquecimento de capoeiras. Revista Árvore, v. 26, n. 6, p. 649-654, 2002.

MCMULLEN, C. K. Flowering plants of the Galápagos. Comstock Publishing Associates, Ithaca, New York, 1999. $370 \mathrm{p}$.

RANIERI, B. D.; LANA, T. C.; NEGREIROS, D.; ARAÚJO, L. M.; FERNANDES, G. W. Germinação de sementes de Lavoisiera cordata Cogn e Lavoisiera francavillana Cogn. (Melastomataceae) espécies simpátricas da Serra do Cipó, Brasil. Acta Botânica Brasílica, v. 17, n. 4, p. 523-530, 2003.

REIS, A.; BECHARA, F. C.; TRES, D. R. Nucleation in tropical ecological restoration. Scientia Agrícola, v. 67, p. 244-250, 2010. 
RODRIGUES, R. R.; LIMA, R. A. F.; GANDOLFI, S.; NAVE, A. G. On the restoration of high diversity forests: 30 years of experience in the Brazilian Atlantic Forest. Biological Conservation, v. 142, p. 1242-1251, 2009.

SAMBA, R. T.; SYLLA, S. N.; NEYRA, M.; GUEYE, M.; DREYFUS, B.; NDOYE, I. Biological nitrogen fixation in Crotalaria species estimated using the $15 \mathrm{~N}$ isotope dilution method. African Journal of Biotechnology, v. 1, n. 1, p. 17-22, 2002.

SANTARÉM, E. R.; AQUILA, M. E. A. Influência de métodos de superação de dormência e do armazenamento na germinação de sementes de Senna macranthera (Colladon) Irwin \& Barneby (Leguminosae). Revista Brasileira de Sementes, v. 17, n. 2, p. 205-209, 1995.

SANTOS, P. L.; FERREIRA, R. A.; ARAGÃO, A. G.; AMARAL, L. A.; OLIVEIRA, A. S. Estabelecimento de espécies florestais nativas por meio de semeadura direta para recuperação de áreas degradadas. Revista Árvore, v. 36, n. 2, p. 237-245, 2012.

SMITH, N. M. Weeds of the wet/dry tropics of Australia - a field guide. Environment Centre, Northern Territory, 2002. $112 \mathrm{p}$.

SOUSA, H. M. H. Avaliação do mata-pasto (Senna obtusifolia L. Irwin \&Baneby) e (Senna uniflora (P. Miller) Irwin \& Baneby) para alimentação de caprinos. 2004. 55 f. Tese (Doutorado em Zootecnia). Centro de Ciências Agrárias - Universidade Federal da Paraíba, Areia, PB, 2004.

SOUZA, S. C. A.; AMARAL, V. B.; MORAIS, F.; LUZ, G. R.; NUNES, Y. R. F.; REIS-JÚNIOR, R. Escarificação de sementes de Senna espectabilis (DC) Irwin Et Barn. (Fabaceae-Caesalpinioideae). In: IX SIMPÓSIO NACIONAL DE CERRADO e II SIMPÓSIO INTERNACIONAL DE SAVANAS TROPICAIS, 2008, Brasília. Anais... Brasília: Embrapa, 2008, 7 p.

SOUZA, V. C.; BORTOLUZZI, R. L. C. 2012. Senna in Lista de Espécies da Flora do Brasil. Jardim Botânico do Rio de Janeiro. Disponível em: < http://floradobrasil. jbrj.gov.br/jabot/listaBrasil/FichaPublicaTaxonUC/ FichaPublicaTaxonUC.do?id=FB23161>. Acesso em: 28 maio 2014.

SPRENT, J. I. Nodulation in legumes. London: Royal Botanic Gardens, 2001. 146 p.

WAGNER, W. L.; HERBST, D. R.; SOHMER, S. H. Manual of the flowering plants of Hawaii. Revised edition. Bernice P. Bishop Museum Special publication. University of Hawaii Press/Bishop Museum Press, Honolulu, 1999. 